\title{
Identifikasi Telur dan Larva Nematode Usus Golongan Soil Transmitted Helmint pada Feces Anak Kelompok Bermain Al Kautsar Mojosongo Kecamatan Jebres Surakarta
}

\author{
Intestinal Nematode Eggs and Larvae Identification of Soil Transmitted Helmint Group on Children \\ Preschool Feces Al Kautsar Mojosongo District of Jebres.
}

Tri Mulyowati*

Fakultas Ilmu Kesehatan Universitas Setia Budi *Corresponding author: trimulyowatiusb81@gmail.com

\begin{abstract}
ABSTRAK
Infeksi kecacingan di Indonesia masih menjadi permasalahan terutama di beberapa daerah di pedesaan. Faktor penting untuk penyebaran penyakit adalah kontaminasi tanah dengan tinja. Telur bisa tumbuh di tanah liat, lembab dan teduh, pemakaian tinja sebagai pupuk kebun merupakan sumber infeksi. Tujuan penelitian ini adalah untuk mengetahui apakah anak - anak kelompok Bermain Al Kautsar di Mojosongo Jebres Surakarta terinfeksi telur, larva nematoda usus golongan Soil Transmitted Helmint dan berapa porsentase yang positip telur, larva nematoda usus golongan Soil Transmitted helmint. Metode yang dipakai dalam pemeriksaan ini adalah menggunakan metode langsung yaitu menggunakan reagen lugol atau eosin. Hasil pemeriksaan makюskopis menunjukkan bahwa semua sampel tidak menunjukkan tanda-tanda abnormal dan hasil mikroskopis semua sampel menunjukkan bahwa 13 feces anak-anak Kelompok Bermain Al Kautsar semuanya tidak ada yang ditemukan telur, larva nematoda usus golongan Soil Transmitted Helmint
\end{abstract}

Kata kunci: telur, larva, nematoda usus, Soil Transmitted Helminth

\section{ABSTRACT}

Worm infection in Indonesia is still a problem, especially in some areas in the countryside. The important factor for the spread of disease is soil contamination with feces. Eggs can grow in clay, moist and shady, use feces as fertilizer garden is a source ofinfection.

The purpose of this study was to determine whether the Al Kautsar Playing Group Children in Mojosongo Jebres infected eggs, larvae intestinal nematodes class Soil nd how porsentase positive eggs, larvae intestinal nematodes Soil Transmitted helmint group.

The method used in this examination is the direct method which uses Lugol reagent or eosin. Macroscopic examination results showed that all samples showed no abnormal signs and microscopic results showed that all 13 fecal samples of Al Kautsar Playing Group Children all nothing was found eggs, larvae intestinal nematodes class of Soil Transmitted Helmint

Keyword: egg.larvae, intestinal nematode, Soil Transmitted helmint

\section{PENDAHULUAN}

Infeksi dan penyakit yang disebabkan kelompok cacing penting bagi manusia karena seringkali mempunyai dampak serius pada penderita maupun masyarakat. Infeksi kecacingan bisa ditemukan luas sekali di seluruh dunia, pada umumnya di daerah beriklim tropis. Penyebab penyakit termasuk Soil Transmitted Helmint. Soil Transmitted Helminth merupakan salah satu penyakit Neglected Tropical Diseases /penyakit tropis yang terabaikan pada beberapa negara. Soil Transmitted Helminths (STH) adalah infeksi cacing usus yang ditularkan melalui tanah. Daerah yang panas, kelembaban tinggi dan sanitasi lingkungan dan kebersihan pribadi yang kurang, mengkonsumsi makanan atau sayuran yang terkontaminasi telur cacing, tingkat pengetahuan dan tingkat ekonomi yang rendah sangat menguntungkan bagi Soil Transmitted Helminths untuk dapat melangsungkan siklus hidupnya. Soil Transmitted Helminths (STH) menyebabkan lebih dari 1 miliar orang telah terinfeksi minimal oleh satu jenis spesies Soil Transmitted Helmint serta menyebabkan masalah kesehatan secara luas selain itu juga 
menyebabkan ketidakmampuan dan beban yang ditanggung masyarakat diukur menggunakan Disability adjusted Life years sebagai bagian dari Global Burden of Disease yang berpengaruh pada kualitas hidup seseorang (Pullan dkk, 2014).

Penyakit cacingan masih banyak menyerang masyarakat Indonesia, terutama anak-anak. Angka prevalensi cacingan masih tinggi di Indonesia mencapai 28,12 persen. Oleh sebab itu, diperlukan langkah pengendalian penyakit ini (Anonim, 2015a). Berdasarkan data terbaru dari WHO sekitar 1,5 miliar orang atau sekitar $24 \%$ dari total populasi dunia menderita infeksi cacingan dan pada umumnya menyerang anak - anak usia sekolah. Banyaknya jumlah anak yang cacingan bisa merugikan negara karena dapat menurunkan kualitas sumber daya manusianya (Anonim, 2015b).

Anak -anak yang terkena cacingan kemungkinan tidak hanya memelihara satu jenis cacing saja di dalam tubuhnya tapi bisa dua atau tiga jenis. Cacing yang umumnya cepat berkembangbiak di tubuh anak - anak di daerah tropis termasuk Indonesia adalah salah satunya Nematoda Usus baik yang golongan Soil Transmitted Helmint dan non Soil Transmitted Helmint di antaranya yang termasuk golongan Soil Transmitted Helmint adalah Ascaris lumbricoides, Trichuris trichiura, cacing tambang dan yang bukan golongan Soil Transmitted Helmint adalah Oxyuris vermicularis.

Pemerintah Indonesia terus berupaya untuk mengurangi infeksi kecacingan dengan mempromosikan dengan penyuluhan mengenai gaya hidup sehat dan sanitasi yang bersih, buang air besar tidak sembarang tempat. Di Jakarta pada penanggulanagan cacing -cacing yang ditularkan melalui tanah berbasis sekolah telah dilakukan penyuluhan para murid, guru dan orang tua di mana diberi perhatian khusus terhadap cara pencegahan infeksi cacing (Margono dan Hadidjaja, 2011). Menurut World Health Organization angka Prevalensi menjadi dasar untuk pemberian intervensi pengobatan. Untuk daerah dengan pre- valensi sekitar 20 hingga 50 persen pemberian obat dilakukan secara massal satu kali dalam setahun (Octama, 2016).

Beberapa survei di Indonesia menunjukkan bahwa seringkali prevalensi Ascaris yang tinggi disertai prevalensi Trichuris yang tinggi pula. Prevalensi ascaris yang lebih tinggi dari $70 \%$ ditemukan antara lain di beberapa desa di Sumatra (78\%), kalimantan (79\%), Sulawesi ( 88\%), NTM (92\%), dan Jawa Barat (90\%). Di desa tersebut prevalensi trichuris juga tinggi masingmasing $83 \%, 83 \%, 84 \%$, dan $91 \%$ (Sungkar dkk, 2009). Penelitian yang pernah dilakukan oleh Rahayu dkk, pada Siswa SDN 1 Kromengan kabupaten Malang menunjukkan Prevalensi Soil Transmitted Helmint pada siswa SDN 1 Kromengan sebesar $48 \%$ yaitu kategori sedang dengan rincian Ascaris lumbricoides 37,5\%, Trichuris trichiura sebesar $17 \%$ sedangkan penelitian pada peternak di Lingkungan Gatep kelurahan Ampenan Selatan diperoleh hasil prevalensi $90 \%$, yang terdiri dari infeksi Ascaris lumbricoides $80 \%$, infeksi Trichuris trichiura 6,67\%, dan infeksi cacing tambang 3,33\% (Resnhaleksmana, 2014).

\section{METODE}

\section{Tempat dan waktu penelitian}

Penelitian dilakukan di Laboratorium Parasitologi Universitas Setia Budi Surakarta pada bulan Januri - februari 2017

\section{Populasi}

Seluruh murid Kelompok Bermain Al Kautsar Mojosongo Kecamatan Jebres Surakarta

\section{Sampel}

Sampel diambil sebanyak 13 feces dari murid Kelompok Bermain Al Kautsar Mojosongo Kecamatan Jebres Surakarta.

\section{Prosedur}

1. Persiapan pengambilan Sampel faeces

a. Bahan tinja yang akan di periksa dikumpul- 
kan pada tempat yang bersih yaitu penampung dari bahan plastik yang dapat ditutup rapat dan tidak boleh tercampur dengan air seni penderita, minyak, garam aluminium, magnesium, barium dan bismuth.

b. Setelah tinja terkumpul maksimal 1 jam diperiksa di Laboratorium

c. Setiap penampung yang berisi tinja diberi formulir /identitas pasien

d. Tinja yang diperlukan untuk pemeriksaan parasitologis sekurang-kurangnya $4 \mathrm{ml}$

2. Pemeriksaan Feces metode langsung

a. Pemeriksaanmakroskopis

Sebelum dilakukan penmeriksaan mikroskopis, dilakukan pemeriksaan makroskopis dengan memperhatikan konsistensi dan tanda-tanda abnormal.

b. Pemeriksaan mikroskopis

Alat dan bahan: Gelas benda, gelas penutup, lidi, pensil untuk label, larutan eosin.

(1) Mencampur $2 \mathrm{mg}$ feces dengan setetes larutan eosin di atas obyek glass

(2) Feces yang masih ada partikel kasar di buang

(3) Feces yang sudah tercampur dengan eosin ditutup dengan gelas penutup, diamati di bawah mikroskop dengan obyektif 10x, atau 40x

(4) Interprestasi hasil
(+) ditemukan telur Nematoda usus golongan Soil Transmitted Helmint pada sediaan feces

(-) tidak ditemukan telur dan larva Nematoda Usus golongan Soil Transmitted Helmint pada sediaan feces (Prasetyo, 2012)

\section{HASIL DAN PEMBAHASAN}

1. Hasil Pemeriksaan Makroskopis (Tabel 1)

2. Hasil Pemeriksaan Mikroskopis dengan metode langsung

Hasil pemeriksaan terhadap 13 sampel feces pada anak Kelompok Bermain Al Kautsar Kecamatan Jebres Surakarta diperoleh hasil negative infeksi nematode usus golongan Soil Transmitted helmint (Tabel 2)

Hasil pemeriksaan mikroskopis dan makroskopis sampel feces anak - anak Kelompok Bermain Al Kautsar Mojosongo Jebres menunjukkan bahwa pemeriksaan makroskopis tdk menunjukkan ciri - ciri abnormal pada feces dan pemeriksaan mikroskopis menunjukkan hasil negatif ditemukan adanya telur, larva nematoda usus golongan Soil Transmitted helmint hal ini dikarenakan anak - anak kelompok Bermain Al Kautsar sudah mulai faham dan mengerti akan pentingnya menjaga higiene pribadi. Letak Sekolah Al

Tabel 1. Hasil pemeriksaan makroskopis sampel feces anak - anak KB Al Kautsar Mojosongo Kecamatan Jebres Surakarta.

\begin{tabular}{|c|l|l|l|c|c|c|}
\hline No sampel & warna & Bau & Konsistensi & lendir & darah & Cacing dewasa \\
\hline 1 & Kuning kecoklatan & khas & Lembek & - & - & - \\
\hline 2 & Coklat & khas & Padat & - & - & - \\
\hline 3 & Kuning kecoklatan & khas & Padat & - & - & - \\
\hline 4 & Coklat & khas & Padat & - & - & - \\
\hline 5 & Kuning & khas & Cair & - & - & - \\
\hline 6 & Kuning & khas & Lembek & - & - & - \\
\hline 7 & Kuning kecoklatan & khas & Padat & - & - & - \\
\hline 8 & Kuning kecoklatan & khas & Padat & - & - & - \\
\hline 9 & Kuning kecoklatan & khas & Cair & - & - & - \\
\hline 10 & Kuning kecoklatan & khas & Lembek & - & - & - \\
\hline 11 & Kuning kecoklatan & khas & Padat & - & - & - \\
\hline 12 & Kuning kecoklatan & khas & Cair & - & - & - \\
\hline 13 & Coklat & khas & lembek & - & - & - \\
\hline
\end{tabular}

Tabel 2. Persentase hasil pemeriksaan telur, larva Nematoda Usus Gologan Soil Transmitted Helmint pada Anak Kelompok Bermain Al Kautsar Kecamatan Jebres Surakarta

\begin{tabular}{|l|l|l|l|l|}
\hline No & Spesies & Hasil pemeriksaan & Jumlah sampel & Persentase (\%) \\
\hline 1 & Ascaris lumbricoides & Negative & 13 & 100 \\
\hline 2 & Trichuris trichiura & Negative & 13 & 100 \\
\hline 3 & Necator americanus & Negative & 13 & 100 \\
\hline 4 & Ancylostoma duodenale & Negative & 13 & 100 \\
\hline
\end{tabular}


Kautsar kebetulan di belakang kampus Universitas Setia Budi Surakarta dan lokasi tersebut sering dijadikan tempat pengabdian masyarakat baik mahasiswa BEM, KKN maupun para dosen untuk melakukan Tri dharma Perguruan Tinggi dan tidak hanya 1-2 kali mereka melakukan penyuluhan sehingga kesadaran akan menjaga kebersihan sudah tinggi. Penyuluhan menjadi penting sekali dengan menitik beratkan perubahan kebiasaan dan mengembangkan sanitasi lingkungan yang baik sehingga angka kesakitan bisa diturunkan. Setiap rumah di Sekitar Lokasi KB Al Kautsar sudah menggunakan jamban sehingga resiko terjadinya infeksi Soil transmitted helmint bisa terkurangi. Setiap pagi di Sekolah anak anak diajari mempraktekkan PHBS salah satunya adalah cuci tangan menggunakan air mengalir dan menggunakan sabun oleh guru yang mengajar baik sebelum makan dan sesudah Buang Air Besar dan selalu memakai alas kaki ketika anakanak berangkat ke sekolah. Pencegahan yang bisa dilakukan agar terhindar infeksi Soil Transmitted Helmint diantaranya pendidikan kesehatan diberikan pada penduduk untuk membuat jamban yang baik untuk mencegah pencemaran tanah, jika berjalan di tanah selalu menggunakan alas kaki untuk mencegah terjadinya infeksi pada kulit oleh larva filariform cacing tambang, makanan dan minuman harus selalu dimasak dengan baik untuk membunuh telur infektif cacing Trichuris trichiura, menjaga kebersihan perorangan akan mencegah terjadinya infeksi cacing Ascaris (Soedarto, 2016)

\section{KESIMPULAN}

1. Tidak ditemukan adanya telur, larva nematoda usus golongan Soil Transmitted helmint pada sampel faeces anak Kelompok Bermain Al Kautsar Kecamatan Jebres Surakarta

2. Persentase telur Nematoda Usus golongan Soil Transmitted helmint pada Anak Kelompok Bermain Al Kautsar Kecamatan Jebres Surakarta adalah 0\% untuk Ascaris lumbricoides, $0 \%$ untuk Trichuris trichiura, $0 \%$ untuk Necator americanus dan 0\% untuk Ancylostoma duodenale.

\section{DAFTAR PUSTAKA}

Anonim,2015a.Cacingan bisa sebabkan anak kurang Gizi dan kurang Cerdas. http://dinkes.inhukab.go.id/?p=3486. diakses tanggal 27 Januari 2017

Anonim, 2015b. Cacingan'Bukan lagi penyakit Orang Kampung' http://www.cnnindonesia.com/gaya-hidup/20151105194633255-89764/cacingan-bukan-lagi-penyakit-orang-kampung/ diakses tanggal 27 Januari 2017

Octama,2016. Angka prevalensi Cacingan di Indonesia. http:// www.beritasatu.com/kesehatan/319918-angka-prevalensicacingan-di-indonesia-mencapai-2812-persen.html. diakses tanggal 27 januari 2017

Margono S.S, Hadidjaja.P.2011.Dasar Parasitologi Klinik. Jakarta : Badan Penerbit FKUI.

Prasetyo, R.H.2002. Pengantar Praktikum Helmintologi kedokteran. Surabaya :Airlangga University Press.

Pullan RL, Smith JL, Jasrasaria R, Brooker SJ.2014. Global Number of infection and disease burder of Soil Transmitted helmint infection in 2010.Parasit Vector; 7(37)

Rahayu, S.E. Suarsini, E. Andini,A.Prevalensi kecacingan Soil Transmitted Helminth pada siswa SDN 1 Kromengan Kabupaten Malang.Universitas Negeri Malang.

Resnhaleksmana,E.2014. Prevalensi nematoda usus golongan Soil Transmitted Helmint pada Peternak di Lingkungan Gatep Kelurahan Ampenan Selatan. Jurnal Media Bina Ilmiah. Volume 8 No 5.

Soedarto, 2016. Buku Ajar parasitologi Kedokteran. Edisi ke dua cetakan Pertama. Jakarta: Sagung Seto.

Sungkar, S. Sutanto, I. Sjarifuddin, P. K. Ismid, I. S. 2009. Buku Ajar Parasitologi Kedokteran.Edisi keempat. Jakarta: Departemen Parasitologi FKUI.

WHO,2011. Soil-Transmitted Helmintted Helminthiasis: Estimates of the Number of Children Needing Preventive Chemotherapy and Number Treated in 2009. 